\title{
Livros ao mar-Circulação de obras de Belas Letras entre Lisboa e Rio de Janeiro ao tempo da transferência da corte para o Brasil*
}

\author{
Márcia Abreu**
}

O objetivo desse artigo é analisar o impacto causado pela transferência da corte portuguesa para o Rio de Janeiro sobre a circulação de obras de Belas Letras na cidade. A partir de 1808, não apenas se tornou possível publicar obras na América Portuguesa, como cresceu o comércio de livros, vindos de Lisboa e de diversos outros portos do mundo. Além disso, pela primeira vez obras impressas no Rio de Janeiro passaram a ser remetidas para comercialização em Lisboa.

Palavras-chave: Leitura - Belas Letras - Romance

\footnotetext{
*Artigo recebido em outubro de 2007 e aprovado para publicação em dezembro de 2007. Esse trabalho é parte do Projeto Temático Caminhos do romance no Brasil: séculos XVIII e XIX, financiado pela Fapesp. Conta também com o financiamento do CNPq, sob a forma de bolsa de produtividade em pesquisa. Resultados das pesquisas realizadas no interior do projeto estão disponíveis no site www.caminhosdoromance.iel.unicamp.br. Agradeço a Lúcia Maria Bastos P. Neves por ter me chamado a atenção para dois documentos fundamentais para esse artigo: a Carta a Domingos de Souza Coutinho, escrita por João Guilherme Christiano, e o pedido para liberação de livros na Alfândega feito por Daniel Pedro Müller.

${ }^{* *}$ Professora Livre-docente do Departamento de Teoria Literária do Instituto de Estudos da Linguagem da Unicamp. E-mail: marcia.a.abreu@gmail.com.
} 
Books at sea - Circulation of Fine Letters books between Lisbon and Rio de Janeiro with the Portuguese court in Brazil

This article analyses the impact caused by the transfer of Portuguese court to Rio de Janeiro on the circulation of Fine Letters books. From 1808 onwards, the book trade flourished. Brazil started to receive books from several other countries besides Portugal. Moreover it was made possible to print books in Portuguese America, which caused and inversion of the flow of books, for some of them were sent to be sold in Portugal.

Key words: Reading - Fine Letters - Novel

Livres à la mer - Circulation d'oeuvres de Belles Lettres entre Lisbonne et Rio de Janeiro à partir du déplacement de la Cour portugaise à Rio de Janeiro Avec cet article on essaie d'analyser l'effet provoqué par le déplacement de la Cour portugaise sur la circulation d'oeuvres de Belles Lettres à Rio de Janeiro. Depuis 1808, il est devenu non seulement possible de publier des oeuvres dans l'Amérique portugaise, comme aussi bien s'est développé un commerce de livres, en provenance de Lisbonne et d'autres parties du monde. D’un autre côté, pour la première fois des oeuvres imprimées à Rio de Janeiro pouvaient être envoyées et mises en vente à Lisbonne.

Mots-clés: Lecture - Belles Lettres - Roman

Na noite entre 25 e 26 de novembro de 1807, João Guilherme Christiano Müller não pôde dormir tranqüilo. Como relatou em carta a Domingos de Souza Coutinho, foi acordado, no meio da madrugada, por "hum Correio", que trazia uma ordem de D. Antonio de Araújo e Azevedo: "mandar ecachotar com toda pressa, tudo quanto da Secretaria de estado estava debaixo da [sua] inspecção, e de manda-lo a Bordo, da Náo Medusa, com aquelles dos Obreiros, que tãobem quisessem ir". ${ }^{1}$ A importância e urgência da ordem eram expressas no fato de Araújo ter escrito, "com sua propria letra”, um pedido para que Müller empregasse toda sua "actividade na prompta execução desta Ordem".

Essa correspondência envolve três importantes personagens da cena portuguesa às vésperas da transferência da corte para o Brasil.

\footnotetext{
${ }^{1}$ João Guilherme Christiano Müller. Carta a Domingos de Sousa Coutinho tratando da arrumação dos livros do senhor Araújo e sobre o funcionamento da Impressão Regia sob ordens dos franceses. [S.1.], 10/01/1808, 4p. Original manuscrito. Biblioteca Nacional do Rio de Janeiro, I-29,20,1, n. 88. Coleção Linhares. Na transcrição dos documentos foram mantidas a ortografia e a pontuação originais.
} 
Domingos de Souza Coutinho, o destinatário da carta, era ministro da corte em Londres, desde 1802, e envolvera-se ativamente na busca de uma solução para a crise entre Portugal, França e Inglaterra de 1807. Assim como seu irmão, Rodrigo de Souza Coutinho, tomara a defesa do chamado "partido inglês" e aborrecera-se fortemente com a notícia de que Portugal aderira ao bloqueio continental e fechara os portos à Inglaterra. ${ }^{2}$ Mantendo sua estratégia de tentar agradar as duas potências em conflito, D. João tomara essa atitude para tentar acalmar os franceses, que exigiam não apenas o fechamento dos portos, mas também a expulsão dos britânicos e a apropriação de seus bens. Ao mesmo tempo em que cedia parcialmente à França, o príncipe regente investiu Domingos de Souza Coutinho de plenos poderes para tratar secretamente com a Inglaterra as formas de compensação pelo fechamento dos portos lusitanos aos ingleses. ${ }^{3}$ Enquanto isso, seu irmão agia em Lisboa, com o propósito de convencer o príncipe regente D. João a negociar com a Inglaterra, rompendo com a França e transferindo a corte para o ultramar. ${ }^{4}$

D. Antonio de Araújo e Azevedo, cujas ordens são relatadas na carta, acumulava, então, duas pastas (ministro e secretário de Estado dos Negócios Estrangeiros e da Guerra, em Lisboa, desde 1804, e Ministro do Reino, desde 1806) e era adepto do chamado "partido francês", razão pela qual tentara, até o último momento, chegar a um entendimento com Napoleão Bonaparte. Quando, na noite de 24 de novembro, participou da reunião do conselho convocada por D. João e soube que Bonaparte tornara pública sua decisão de destronar a casa de Bragança, fazendo imprimir no periódico Le Moniteur o tratado firmado com a Espanha, pelo qual os dois países dividiriam o território português, perdeu as esperanças. O conselho decidiu que o governo deveria se entender com os ingleses e preparar imediatamente o embarque de toda a família real para o Brasil. ${ }^{5}$ Araújo não perdeu tempo e enviou, no dia seguinte, a ordem recebida por Müller, no meio da madrugada.

João Guilherme Christiano Müller, assim como o príncipe regente, ocupava um curioso lugar entre ingleses e franceses. Provavelmente, travou

${ }^{2}$ Cartas a Sua Alteza Real. FBN - ms. 10,3,29. Apud Lilia Mortiz Schwarcz (com Paulo César de Azevedo e Ângela Marques da Costa). A longa viagem da biblioteca dos reis - do terremoto de Lisboa à Independência do Brasil, São Paulo, Companhia das Letras, 2002, p. 206.

${ }^{3}$ Oliveira Lima, D. João VI no Brasil, Rio de Janeiro, Topbooks, 1996, p. 46, 1. ed., 1908.

4 "Representação feita pelo D. Rodrigo de Sousa Coutinho, oferecida ao príncipe de Portugal, em 16 de outubro de 1807". IHGB, pasta 214, doc. 8. Apud Lilia Mortiz Schwarcz (com Paulo César de Azevedo e Ângela Marques da Costa). A longa viagem da biblioteca dos reis - do terremoto de Lisboa à Independência do Brasil, São Paulo, Companhia das Letras, 2002, p. 203.

${ }^{5}$ A longa viagem da biblioteca dos reis..., p. 207. 
conhecimento com Domingos de Souza Coutinho por ocasião de sua estada em Londres, como acompanhante do príncipe Frederico Augusto, duque de Sussex, de quem fora camareiro, quando de sua permanência em Lisboa. No momento da partida do duque para a Inglaterra, Müller o acompanhou, regressando a Lisboa apenas em $1806 .{ }^{6}$ Nesse mesmo ano, entrou para o serviço de D. Antonio de Araújo e Azevedo, segundo relata em sua carta: "Eu passei quasi toda a primeira metade deste ultimo anno em Caza do $S^{r}$. Araujo, que me mandou chamar na vespera do dia de Natal de 1806, e me confiou o arranjo d'huma multidão de livros, Mappas, Estampas, e outros papeis"?

Müller tinha muita familiaridade com livros e documentos. Ele chegara a Lisboa, em 1773, vindo da Alemanha para ser pastor da Congregação Luterana. Protestante, conseguiu ser bem acolhido graças à sua erudição, que lhe abriu as portas da "sociedade dos homens sábios e dos honestos cidadãos" da cidade. ${ }^{8}$ A boa convivência com letrados portugueses e sua forte cultura humanística o conduziram à Academia Real de Ciências de Lisboa, fundada em 1779, da qual se tornou sócio supranumerário em 1787, acumulando os trabalhos intelectuais produzidos para a instituição com o exercício das funções de pastor. ${ }^{9}$ Três anos depois, disputas internas à comunidade luterana

\footnotetext{
${ }^{6}$ Müller concluiu sua carta a Coutinho fazendo referência aos amigos comuns: "Espero, que os amigos de Londres naõ se tenhaõ esquecido totalmente de mim, eu me lembro muitas, e muitas vezes com saudosos desejos de ainda ve-los antes de morrer dos $\mathrm{S}^{\mathrm{rs}}$. Daniel Artur, Ambrosio, e de todos, que me favorizarão com a sua compagnia, e serviços beneficos em quanto estive em Londres".

${ }^{7}$ João Guilherme Christiano Müller. Carta a Domingos de Sousa Coutinho, op. cit.

${ }^{8}$ Sua biografia foi apresentada por Francisco Manuel Trigoso de Aragão Morato, seu colega na Academia de Ciências de Lisboa, na Assembléia Pública de 24 de junho de 1815. Para compor seu texto, Morato fez várias pesquisas bibliográficas sobre Müller e sua família, consultou documentos oficiais, e uma "minuta original de d'huma carta que elle [Müller] escrevia pelos annos de 1803, a pessoa que o consultava sobre sua Patria, Pais, e Estudos", além, é claro, de valer-se de seu contato pessoal com Müller. [Morato, Francisco Manuel Trigoso de Aragão, Elogio histórico de João Guilherme Christiano Muller, in tomo IV, parte II, das Memórias da Academia Real das Ciências de Lisboa, lic. Paul Wilhelm Gennrich]. João Pedro Ferro arrola os bons relacionamentos de Müller com homens ricos, influentes e cultos residentes em Lisboa. [João Pedro Ferro. "Intelectuais alemães em Portugal: Johann Wilhelm Christian Müller (1752 - 1814)", in Portugal - Alemanha - África. Lisboa, Colibri, 1996, p. 315 e segs]. Sobre a vida de João Guilherme Christiano Müller em Portugal, ver também: Eduardo Moreira, Vidas convergentes, Lisboa, Junta Presbiteriana de Cooperação em Portugal, 1959, e João Pedro Ferro, Influências germânicas em Portugal na segunda metade do século XVIII, Separata das Atas do Congresso Internacional Portugal no século XVIII de D. João V à Revolução Francesa, Sociedade Portuguesa de Estudos do Século XVIII, Universitária Editora, Lisboa, 1991.

${ }^{9}$ Sobre o ingresso de um protestante na Academia, João Pedro Ferro comentou: "A entrada do pastor protestante alemão para a Academia das Ciências foi um caso extraordinário mas não único. Reflectia, por um lado, o avanço e a tolerância cultural daquela agremiação e, por outro, os reflexos das idéias de alguns dos seus dirigentes, 'estrangeirados', habituados a contactar com sábios de todas as religiões", João Pedro Ferro, "Intelectuais alemães", op. cit., p. 317.
} 
fizeram com que ele aceitasse o convite do ministro e secretário de Estado da Fazenda, visconde de Vila Nova de Cerveira, futuro marquês de Ponte de Lima, para que ingressasse em seu serviço, deixando de ser pastor - sem, entretanto, abandonar o luteranismo. No ano seguinte, em 23 de novembro de 1791, converteu-se ao catolicismo e naturalizou-se português, recebendo, a partir de então, uma série de nomeações, entre as quais a de Deputado Ordinário da Real Mesa da Comissão Geral sobre o Exame dos Livros, em 16 de maio de $1792 .{ }^{10}$ Nessa função, juntamente com seus colegas reunidos na Mesa, desempenhava um importante papel: definir as obras que poderiam ser impressas e os livros que podiam circular em Portugal e seus domínios.

Se, nesse momento, não vamos nos centrar na ação específica de Müller, ${ }^{11}$ vamos nos valer de sua figura como censor e de seu papel nos acontecimentos ocorridos nos dias que antecederam a viagem da família real para o Brasil "como hum testemunho ocular da ultima fatal catastofre deste Reino", segundo escreveu a Souza Coutinho -, como forma de aproximação ao tema que nos interessa aqui: a circulação de livros entre Portugal e o Brasil no período colonial.

Até 1807, a única possibilidade legal de acesso a livros e papéis impressos aberta aos que viviam na América portuguesa era importá-los de Portugal, o que implicava, necessariamente, a elaboração de um pedido de autorização ao órgão de censura lusitano ativo no momento. ${ }^{12} \mathrm{O}$ controle estrito sobre material

${ }^{10}$ João Guilherme Christiano Müller foi nomeado Deputado Ordinário da Real Mesa da Comissão Geral sobre o Exame e Censura dos Livros, em 16 de maio de 1792. [Arquivos Nacionais da Torre do Tombo (doravante chamado ANTT), Ministério do Reino, liv. 364, fl. 83v-84.] A carta do deputado data de 2 de junho de 1792. [ANTT, Chancelaria de D. Maria I, liv. 41, fl. 94v.].

${ }^{11}$ Sobre a atuação de João Guilherme Christiano Müller como censor, ver: "Effluvios pestiferos da perversidade do Século", leituras de Werther no mundo luso-brasileiro, Revista de Letras, Universidade Estadual Paulista, vol. 46, n. 2 (jul-dez 2006), p. 78-95.

${ }^{12}$ Em Portugal, a censura aos impressos teve início no século XVI, em momento muito próximo ao da produção do primeiro livro, que parece ter sido publicado em Chaves, em 1489. A atividade censória repartia-se entre o Ordinário (juízes eclesiásticos ligados às dioceses, em atuação desde 1517), o Tribunal do Santo Ofício (organismo ligado à Igreja, em funcionamento desde 1536) e o Desembargo do Paço (órgão censor ligado ao poder régio, atuante a partir de 1576). Esse sistema tríplice esteve em atuação até 1768, quando D. José I julgou ser necessário centralizar a censura em um só organismo, criando, assim, a Real Mesa Censória, a qual foi substituída, em 1787, pela Real Mesa da Comissão Geral para o Exame e a Censura dos Livros, por ordem de D. Maria I. Em 17 de dezembro de 1794, extinguiu-se a Real Mesa da Comissão Geral sobre o Exame e Censura dos Livros e retornou-se à censura tríplice, a cargo do Santo Ofício, autoridade episcopal e Desembargo do Paço. A atuação do Ordinário e do Santo Ofício permaneceu até $1^{\circ}$ de outubro 1820, quando foi suspensa. Por Portaria de 21 de setembro de 1820, todas as atribuições que pertenciam ao Desembargo do Paço foram transferidas para a Comissão de Censura. Em 31 de março de 1821, as Cortes Gerais Extraordinárias da Nação decretaram a extinção do Santo Ofício. No mesmo ano, a Carta de Lei de 16 de julho aboliu a censura, que, entretanto, foi reinstituída em 1824, por Decreto de 6 de março, que restabeleceu a censura a cargo do Desembargo e do Ordinário, situação que perdurou até 1832, quando foi abolida a censura preventiva. Ver: Márcia Abreu, Os caminhos dos livoros, Campinas, Mercado de Letras/ALB/Fapesp, 2003; José Timóteo da Silva Bastos, História da censura intelectualem Portugal:ensaio sobre a compreensão do pensamento português, Lisboa, Moraes Editores, 1983, 2. ed., p. 70.; Graça Almeida Rodrigues, Breve história da censura em Portugal, Lisboa, Instituto de Cultura e Língua Portuguesa, 1980; Luiz Carlos Villalta, Reformismo ilustrado, censura e práticas de leitura; usos do livro na América portuguesa, São Paulo, FFLCH-USP, 1999, Tese de Doutorado. 
impresso atingia não apenas aqueles que viviam nas distantes colônias, mas recaía sobre todo e qualquer súdito que quisesse ter nas mãos um livro, sem se arriscar às severas punições a que estavam sujeitos todos os que possuíam, liam ou transportavam livros sem as devidas autorizações. Aqueles que temiam a ilegalidade tinham que proceder como Lourenço Pereira da Costa, por exemplo, que, em fevereiro de 1769, se dirigiu à Real Mesa Censória, declarando:

que vindo de Servir a V. Magde de Ouvidor do Ryo Negro destricto do Graõ Pará, trouxe osSeus Livros, cujos Se lhe emtregaraõ depois deSerem vistos nesta Real Meza Censoria, e como pertende fazer hir os mesmos Livros para aVilla de Redondo aonde esta morador, epara que nas Alfag. das $\mathrm{p}$ onde passar Se lhe naõ ponha embaraço algu P aV. Mag. de Seja Servido Concederlhe aLicença requerida. ${ }^{13}$

Mesmo estando a serviço do rei, teve de cumprir todas as formalidades, que faziam com que um mesmo conjunto de livros passasse diversas vezes pelos organismos de censura. Ao se dirigir ao Brasil, para atuar como ouvidor no Grão-Pará, Lourenço Pereira da Costa teve de obter licença para sair de Portugal com seus livros. Caso tenha decidido adquirir novas obras durante o período em que viveu em Rio Negro, teve de solicitar autorizações em Lisboa a fim de obter licenças para fazer remeter os volumes para o Brasil. No momento de regressar a Portugal, foi obrigado a elaborar uma nova lista de livros - na qual referia os títulos para os quais já solicitara licença anteriormente, quando de sua remessa de Lisboa para o Brasil - e pedir mais uma vez autorização para que as obras pudessem regressar a Portugal. Como não vivia em Lisboa, assim que conseguiu pôr a mão sobre seus livros, "depois deSerem vistos nesta Real Meza Censoria", teve de elaborar mais um pedido de licença, dessa vez para transportá-los de Lisboa para a Vila de Redondo, onde vivia. Para cada um desses pedidos, era designado um censor, o qual examinava a lista, visando detectar títulos proibidos ou potencialmente perigosos. Se nada fosse encontrado, o requerente obtinha a licença que desejava. Em caso de localização de obra proibida ou declarada inadequada pela censura, o livro era retido junto ao tribunal censório ou, na melhor hipótese, remetido

13 “Catálogos - Exame dos livros para circulação no Reino”, ANTT, Real Mesa Censória (doravante chamada RMC), caixa 146. 
de volta ao lugar de onde havia sido enviado, em caso de impresso adquirido fora do Reino. ${ }^{14}$

Todo esse meticuloso controle caiu por terra no final de 1807, quando, finalmente, se decidiu que a família real deveria embarcar para o Brasil.

João Guilherme Christiano Müller não foi o único a dormir mal na noite de 25 de novembro. À meia-noite, Joaquim José de Azevedo, futuro visconde do Rio Seco, foi chamado ao Palácio da Ajuda e nomeado "superintendente geral do embarque". No dia seguinte, dirigiu-se para o cais de Belém, onde mandou armar uma barraca "para dali repartir as famílias pelas embarcações, segundo a escala de seus cômodos, assim como para enviar todos os volumes do Tesouro que chegavam, lida que continuou até o momento de embarque de d. João". ${ }^{15}$ Apesar do desejo de manter sob controle o material embarcado, a pressa, a quantidade de bens e pessoas a transportar e a chuva contínua que caía sobre Lisboa tornavam a tarefa impossível.

Em sua carta Müller narrou as dificuldades de fazer embarcar o material de que tão zelosamente cuidara:

No dia de 27 a tarde forão 37 grandes Caixotes a Bordo. A chuva copiosa neste dia, e o tempo procelloso impedio de ir taobem o Tresor, e a Caixa do Segredo da Caza. Mas estas forão no dia seguinte accompanhadas por meu adjudante, e com hum breve escrito meu, no qual dizia, que o portador daria boccalmente conta das transacções do dia antecedente.

Chegando isto a Náo, naõ queria aceitar mais coisa alguma. Mostrando porem o meu adjudante a minha Carta, e chamando por hum Official da Secretaria, que la havia, embarcarão as Caixas, mas não permittiraõ que subisse o Messageiro dizendo: que o $S^{r}$. Araujo naõ estava a bordo, e que naõ podia mais receber pessoa alguma.

Na noite daquelle mesmo dia, ainda ninguem se capacitava da partida repentina da Corte, e eu esperava ainda alguma resposta, ou ulterior Ordem - Mas no dia seguinte, que era o mais sereno que imaginar se pode, com o amanhecer, ja tudo se fez vella, e navegava a barra para fora. ${ }^{16}$

\footnotetext{
${ }^{14}$ Para um detalhamento dos procedimentos de censura relativos à circulação de livros, ver: Márcia Abreu, Os caminhos dos livros, Campinas, Mercado de Letras/ALB/Fapesp, 2003.

${ }^{15}$ Exposição analítica e justificativa de conduta, e vida pública do visconde do rio Seco, desde o dia 25 de novembro de 1807, em que sua majestade fidelissima o incumbiu dos arranjamentos necessários de sua retirada para o Rio de Janeiro, até o dia 15 de setembro de 1821, em cujo ano demitira todos os lugares e empregos de responsabilidade de fazenda com permissão de sua alteza real o regente do Brasil, concedida por decreto de 27 de agosto do presente ano, publicada por ele mesmo, Rio de Janeiro, Imprensa Nacional, 1821, FBN/SOR, 37, 17, 1, p. 5. Apud Schwarcz, op. cit, p. 210. ${ }^{16}$ João Guilherme Christiano Muller, Carta a Domingos de Sousa Coutinho, op. cit.
} 
Temendo a confusão e o atropelo geral, Antonio de Araújo e Azevedo tinha embarcado durante a noite, na nau Medusa, para a qual foram encaminhados os documentos oficiais, bem como seus livros e papéis pessoais, e que zarparia, junto com o restante da esquadra, rumo ao Brasil em 29 de novembro de $1807 .{ }^{17}$ João Guilherme Christiano Müller tinha organizado listagens dos livros e cuidado de sua acomodação em caixas apropriadas, que foram embarcadas junto com seu proprietário, sem que, entretanto, tivessem sido submetidos a exame pela censura. Na confusão, apesar das diligências tomadas por Joaquim José de Azevedo, não houve qualquer tipo de controle sobre os livros e papéis embarcados, o que pode ter permitido que muitos carregassem consigo os livros de sua predileção, sem que, pela primeira vez, em séculos, fossem incomodados por qualquer tipo de controle.

A nau Medusa, na qual viajava Antonio de Araújo e Azevedo, juntamente com os livros e papéis organizados por Müller, além de um conjunto de equipamentos tipográficos, uma coleção mineralógica e o instrumental necessário para instalar um laboratório de química, foi a primeira a atracar no Brasil, chegando ao Recife em 13 de janeiro de 1808, após 45 dias no mar. ${ }^{18}$

A Biblioteca Régia, também conhecida como Livraria Real ou Real Biblioteca, com cerca de 60 mil peças (livros, estampas, manuscritos, moedas e mapas), não teve semelhante sorte. No mesmo dia em que a esquadra portuguesa partiu, Alexandre Antônio das Neves, encarregado da Livraria Real, percebeu que seria impossível executar a ordem régia "de se queimarem, logo depois da sua saída barra-fora, os papéis que existiram nos Gabinetes destas suas bibliotecas", pois "dos muitos caixões de livros prontos para o embarque, nem um só chegou a recolher-se do cais para bordo". Se o abandono no porto causara consternação, em carta de 12 de outubro de 1808, Neves informava, satisfeito, que "nem um só livro ou papel foi tirado destas Reais Bibliotecas pelos franceses". ${ }^{19}$ As sucessivas investidas dos franceses, no entanto, faziam temer pela sorte dos livros mais preciosos; assim, a partir de 1809, foram

\footnotetext{
${ }^{17}$ João Manuel Pereira da Silva, História da fundação do império do brasileiro, Rio de Janeiro, Garnier, 1864, p. 121, Biblioteca do Instituto de Filosofia e Ciências Humanas, Unicamp, 981.033, Si 38h, v. 1.

${ }^{18}$ Para um estudo sobre a biblioteca do conde da Barca, ver Maria Beatriz Nizza da Silva, Cultura e sociedade no Rio de Janeiro (1808-1821), São Paulo, Cia. Editora Nacional, 1978.

${ }^{19}$ Domingos, Manuela D., "Biblioteca Nacional de Portugal”, Lisboa, Associação Nacional de Bibliotecas Nacionais Ibero-Americanas, 1994 (manuscrito). Apud Lilia Moritz Schwarcz, "D. João VI e os livros no Brasil: o caso da real biblioteca", in http://www.realgabinete.com.br/ coloquio/3_coloquio_outubro/paginas/14.htm\#_ftnref17
} 
organizadas três remessas de livros, transferindo a Real Biblioteca para o Rio de Janeiro, o que só se completaria em setembro de $1811 .^{20}$

Embarcados os livros, papéis e máquinas que acompanharam Antonio de Araújo e Azevedo, João Guilherme Christiano Müller permaneceu em Portugal, cuidando do que restou. Dentre suas várias ocupações, estava a de diretor da Impressão Régia, o que o levou a lidar diretamente com os franceses. E não teve muito boa impressão deles:

Presentemente estou fixo na Impressão Regia, sempre prompto ás Ordens dos Generaes francezes, para traduzir, mandar imprimir, e corrigir huma multidão de Decretos, Ordens, e outros papeis do uso do Exercito estrangeiro. Porque eu sou o unico dos Directores destes Instituto, que possa se explicar com estes hospedes. Em geral naõ saõ muito letrados, e escrevem a sua propria lingua naõ com a maior perfeiçaõ. Ja succedéo, que se corrigiraõ Originais sobre as Traducções, que dellas se fizeraõ. ${ }^{21}$

Mesmo ocupado com a Direção da Impressão Régia de Lisboa e com as ordens dos franceses, João Guilherme Christiano Müller continuava a atuar como censor, controlando os livros que poderiam ser enviados para a corte, agora instalada nos trópicos, e para os demais moradores do Brasil. Apesar do tumulto político causado pelas invasões francesas e pela transferência da família real para o Rio de Janeiro, o sistema de censura, que obrigava a obter uma autorização para transportar livros e papéis, continuava ativo, embora muito menos atuante. Se, em 1807, considerando-se apenas os pedidos de autorização para envio de Belas Letras para o Rio de Janeiro, registraram-se 35 pedidos de autorização, no ano seguinte, as solicitações reduziram-se a 12. Os números continuaram a cair com o passar do tempo: em 1810, registrou-se apenas 1 pedido; em 1811, nenhum; em 1812, 1; Eles voltaram a crescer apenas em 1813, quando se registraram 22 requerimentos de autorização para embarque de obras de Belas Letras para o Rio de Janeiro. A partir daí as solicitações de autorização para remessa de livros não pararam de crescer. $^{22}$ Entre 1808 e 1826 - momento em que, após o

${ }^{20}$ Lilia Moritz Schwarcz, "D. João VI e os livros no Brasil: o caso da real biblioteca”, in http:// www.realgabinete.com.br/coloquio/3_coloquio_outubro/paginas/14.htm\#_ftnref17

${ }^{21}$ João Guilherme Christiano Muller, Carta a Domingos de Sousa Coutinho,op. cit.

${ }^{22}$ Em minha pesquisa, restringi a observação apenas às obras de Belas Letras. No início do século XIX, em geral, utilizava-se a seguinte classificação para ordenação de bibliotecas: Belas Letras, Teologia, Ciências e Artes, História e Jurisprudência (com subdivisões internas). Cf. Maria Beatriz Nizza da Silva, "Livro e sociedade no Rio de Janeiro (1808-1821)", in Revista de História, n. 94, 1973.

O maior número de pedidos de licença pede autorização para envio de obras da classe de Teologia, seguido por aqueles que solicitam licença para remessa de livros profissionais. Em terceiro lugar, vêm as obras de Belas Letras, categoria na qual se incluíam poesias, romances, peças teatrais, obras de eloqüência, tratados de retórica e poética, estudos gramaticais etc. Márcia Abreu, Os caminhos dos livros, Campinas, Mercado de Letras/ALB/Fapesp, 2003. 
reconhecimento da independência, Portugal suspendeu o controle do envio de livros para a América -, registram-se 358 pedidos dirigidos à censura com o intuito de obter liberação para envio de 3.003 livros de Belas Letras (relativos a 851 diferentes títulos) de Lisboa para o Rio de Janeiro. Esses números não correspondem ao total de exemplares enviados, pois a censura não controlava o comércio e sim a circulação de idéias, razão pela qual não era necessário especificar a quantidade de exemplares de cada título para o qual se solicitava autorização. Desse modo, o número de exemplares remetidos era certamente muito superior ao de obras referidas nos pedidos de licença. ${ }^{23}$

A diminuição do envio legal de livros para o Brasil, em 1808, parece ter direta relação com a saída da corte de Lisboa. Após dois meses de viagem, com alguns incidentes, tormentas e avarias, D. João e seus acompanhantes, finalmente, chegaram ao Rio de Janeiro. A chegada da corte parece ter sido um espetáculo de estranhamento mútuo. Para os que aportavam, a cidade parecia decepcionante: comprimida entre o mar e manguezais insalubres, era composta por ruas apertadas e sinuosas, com casas pouco vistosas e desconfortáveis. A população, que não chegava aos 60 mil habitantes, era constituída por uma maioria de negros escravos. Para os que viviam no Rio de Janeiro, o encontro com a realeza e seu séqüito também parece ter sido frustrante: a súbita chegada de centenas de pessoas - entre membros da família real, cortesãos, funcionários e criados - transtornadas pela longa e desconfortável viagem, mas ciosas de seus privilégios como nobres e reinóis, causou grandes embaraços nos primeiros tempos. ${ }^{24}$

Passado o momento inicial, eles logo devem ter percebido que tinham muita coisa em comum - ao menos, no que diz respeito às preferências de leitura.

Até 1807, os livros de Belas Letras enviados com mais freqüência de Lisboa para o Rio de Janeiro compunham-se, majoritariamente, de obras de ficção (55\% das obras mais enviadas), entre as quais estavam: Aventuras de Telêmaco, de Fénelon; Historia de Gil Braz de Santilhana, de Lesage; Viajante

\footnotetext{
${ }^{23} \mathrm{Na}$ quase totalidade dos casos, os censores manifestavam-se favoravelmente ao envio dos livros, limitando-se a despachos tão sucintos como "concedem licença", seguidos da data (dia, mês e ano). Os apreciadores do pleonasmo produziam pareceres do tipo: "Concedem licença para os que não forem prohibidos" ou "Concedem licença excepto aos que forem prohibidos". Os títulos proibidos eram de conhecimento público, e dificilmente seria enviado à censura um pedido de autorização para remessa de um livro sobre o qual pesasse interdição.

${ }^{24}$ Lúcia Maria Bastos Pereira das Neves \& Humberto Fernandes Machado, O Império do Brasil, Rio de Janeiro, Nova Fronteira, 1999, p. 30-31.
} 
Universal, ou notícia do Mundo antigo e moderno, de Laporte; História do Imperador Carlos Magno e dos doze pares de França, de autor desconhecido; Carolina de Lichtfield, ou o triunfo da virtude, de Montolieu; O Engenhoso Fidalgo D. Quixote de la Mancha, de Cervantes; Lances da Ventura, acasos da desgraça e heroísmos da virtude, de Monroy y Ros; Viagens de Altina, de Caetano de Campos; O Feliz independente do mundo e da fortuna, do $\mathrm{P}^{\mathrm{e}}$. Almeida; e Viagens de Henrique Wanton, de Seriman. ${ }^{25}$ Após a chegada da corte, a lista de obras preferidas mantém-se surpreendentemente semelhante $(44 \%$ das obras continuam a figurar entre as 10 mais remetidas), permanecendo, também, o interesse por obras ficcionais, que passam a ser responsáveis por $58 \%$ dos títulos mais solicitados: Aventuras de Telêmaco, de Fénelon; As mil e uma noites, de Galland; Historia de Gil Braz de Santilhana, de Lesage; Thesouro de meninas ou diálogo entre uma sábia aia e suas discipulas, de Beaumont; História do Imperador Carlos Magno, anônimo; O Feliz independente do mundo e da fortuna, de $\mathrm{P}^{\mathrm{e}}$. Almeida; Lances da Ventura, acasos da desgraça e heroísmos da virtude, de Monroy y Ros; Thesouro de meninos, de Blanchard; e O Piolho Viajante, de Policarpo da Silva. ${ }^{26}$

O livro Aventuras de Telêmaco, escrito por François de Salignac de la Mothe-Fénélon para instrução do herdeiro do trono francês, de quem era preceptor, conheceu uma primeira edição em 1699, na qual, sob o pretexto de narrar a história do filho de Ulisses em busca do pai, oferecia farta informação sobre cultura clássica, bem como sobre geografia, política, economia e moral. A obra teve extraordinário sucesso, mantendo-se no topo da lista de livros mais vendidos, não apenas em seu país de origem, mas por toda a Europa - e, a se julgar pelo que ocorria no Brasil, possivelmente em todo o mundo ocidental.

A pequena Babel em que se havia transformado o Rio de Janeiro depois de 1808 fazia com que se solicitassem as mais diversas edições do livro, registrando-se pedidos para "Fenelon, Aventures de Telemaque, Paris, 1799",

\footnotetext{
${ }^{25}$ Para este cálculo foi elaborado um ranking das obras mais pedidas e consideradas as 10 primeiras colocações. Entre 1769 e 1807, além dos títulos citados, integram a lista dos preferidos os seguintes livros: Noites, de Edward Young; Seleta Latina, de Pierre Chompré; Meditaçoens do Doutor James Hervey sobre as sepulturas, e sobre vários objectos, de James Hervey; Paraiso Perdido, de John Milton; Rimas, de Manuel Maria Barbosa du Bocage; Fábulas, de Esopo; Obras, de Luís de Camões; e Rimas, de João Xavier de Mattos. Boa parte das obras ficcionais remetidas ao Rio de Janeiro está disponível em versão fac-similar na Biblioteca Virtual do site www.caminhosdoromance.iel.unicamp.br.

${ }^{26}$ Além das obras ficcionais, compõem a lista dos 10 títulos mais remetidos ao Rio de Janeiro as seguintes obras: Seleta Latina, de Chompré; Obras, de Bocage; Horacio ad usum; Marilia de Dirceu, de Gonzaga.
} 
"Adventures of Telemaco", "Telemaco em portuguez”. No século XIX, o sucesso do livro era de tal ordem que se publicavam edições contendo o texto de Fénelon em mais de uma língua, como ocorreu no surpreendente Essai d'un Télémaque polyglotte, ou les Aventures du Fils d'Ulysse en langue française, grecque moderne, arménienne, italienne, espagnole, portugaise, anglaise, allemande, hollandaise, russe, polonaise, illyrienne, avec une traduction en vers grecs et latins, publicado em Paris, em 1812, contendo as histórias do filho de Ulisses em 14 línguas. Edições mais concisas, com versões do texto em duas línguas, eram remetidas para o Rio de Janeiro, conforme se vê em requisições como "Aventuras de Telemaco em francez e Hespanhol", "Aventuras de Telemaco em inglez e Hespanhol”, "Telemaco em inglez e francez". ${ }^{27}$

A partir de 1808, cresceu o número de referências a edições estrangeiras nos pedidos de autorização, o que parece natural, tendo em vista a abertura dos portos e o considerável crescimento da presença de estrangeiros no Rio de Janeiro. Se, no terreno político, Portugal havia se decidido em favor dos ingleses, em detrimento dos franceses, o mesmo não se observa no campo cultural: $46 \%$ dos livros mais enviados foram escritos originalmente em francês, enquanto obras anglo-saxãs, bastante enviadas ao Rio de Janeiro até 1807 (Night Thoughts, de Young, Meditations and Contemplations, de Hervey, e The Paradise Lost, de Milton), passaram a ter uma procura muito inferior. A predominância cultural francesa fica clara, por exemplo, na opção feita pelo tradutor para o português do livro The Life and Strange Surprizing Adventures of Robinson Crusoe of York, Mariner, de Daniel Defoe, que achou por bem deixar claro que as aventuras de Robinson Crusoé haviam sido "traduzidas da língua francesa por Henrique Leitão de Sousa Mascarenhas". ${ }^{28}$

Não obstante a importante presença de livros estrangeiros, é relevante o papel de obras escritas originalmente em português entre as mais solicitadas. Entre 1808 e 1826, estão entre os 10 livros mais remetidos ao Rio de Janeiro os seguintes: Obras, de Bocage; O Feliz independente do mundo e da fortuna, do $\mathrm{P}^{\mathrm{e}}$. Almeida; Lances da Ventura, acasos da desgraça e heroísmos da virtude, de Monroy y Ros; Marilia de Dirceu, de Gonzaga; e O Piolho Viajante, de Policarpo da Silva. Curiosamente, o interesse pelas Obras de Luís de Camões (que, antes da transferência da corte, ocupava o $10^{\circ}$ lugar nas solicitações, passando, após

\footnotetext{
${ }^{27}$ Pedidos submetidos pelo livreiro João Francisco Rolland, em 1820, ANTT, RMC, caixa 156.

${ }^{28} \mathrm{O}$ livro Vida e aventuras admiráveis de Robinson Crusoé, que contêm a sua tornada à sua ilha, as suas novas viagens e as suas reflexões foi publicado em Lisboa em 1785. Grifo meu.
} 
1808, para o $11^{\circ}$ ) parecia menor do que o despertado por obras praticamente desconhecidas, como os romances Lances da Ventura ou O Piolho Viajante. Entretanto, o interesse pelo grande poeta português não se restringia às Obras de Camões, às quais é preciso acrescentar as solicitações relativas a Os Lusíadas - cuja demanda quadruplicou após a transferência da família real.

Se a procura por estas obras permaneceu desde seu lançamento, outras parecem ter sido descobertas tardiamente pelos luso-brasileiros, como ocorreu com As mil e uma noites, cuja primeira edição data de 1704, e que não havia chamado a atenção até 1815 , quando começou a ser remetida diversas vezes ao ano. ${ }^{29}$ Esse "esquecimento" possivelmente se deve ao fato de ser tardia a tradução de As mil e uma noites, vertido para o português apenas em 1801. Considerando o fato de haver tradução disponível para todos os livros mais remetidos para o Rio de Janeiro, é possível supor que os leitores preferissem manter contato com textos em idioma luso.

O fato de ter sido composta em português, entretanto, não garantia uma boa acolhida a toda obra. Publicados pela primeira vez em 1792, os versos de Marilia de Dirceu, de Thomas Antonio Gonzaga, embora compostos no Brasil, não voltaram para cá em letra de forma antes de 1800, data em que se registra a primeira remessa do livro para o Rio de Janeiro. Nesses oito anos, o livro foi um espetacular sucesso em Portugal, conhecendo quatro diferentes edições em Lisboa, uma das quais vendeu 2 mil exemplares em apenas seis meses. ${ }^{30}$ Entre 1800 e 1807, não se verifica grande interesse pelo livro no Brasil, já que se registram apenas oito pedidos, embora seja possível imaginar remessas com quantidades elevadas de exemplares, já que todas as solicitações de autorização de envio foram assinadas por livreiros. ${ }^{31}$ Surpreendentemente, após a transferência da família real - com quem Gonzaga teve tantos dissabores - a procura pelo livro não cessou de crescer, fazendo com que chegasse

\footnotetext{
${ }^{29}$ Até 1807, As mil e uma noites tinham sido enviadas ao Rio de Janeiro apenas 6 vezes. Curiosamente, um dos livros compostos à imitação daquele, Les Mille et un quart-d'heure. Contes Tartares (publicado em Paris em 1715 e traduzido para o português com o título Divertimento de um quarto de hora pelo P. João Silvério de Lima em 1782), despertou maior interesse, tendo sido remetido 9 vezes.

${ }^{30}$ A história editorial de Marilia de Dirceu é bastante complexa nesses primeiros anos, incluindo edições apócrifas e divulgação de poemas de autoria incerta. Veja-se a respeito o prefácio preparado por M. Rodrigues Lapa para a edição Marilia de Dirceu e mais poesias, Tomás Antônio Gonzaga, Lisboa, Livraria Sá da Costa, 1937.

${ }^{31}$ Fizeram remessa Viuva Bertram e Filhos e Francisco Rolland (em 1800); Paulo Martins e, novamente, Francisco Rolland e Viuva Bertram e Filhos (1802); Simão Taddeo Pereira (2 vezes em 1803); Paulo Martins e Filhos (1807), ANTT, RMC, caixas 153 e 154.
} 
a figurar entre as 10 obras pelas quais se verificava maior procura. ${ }^{32}$ Seu envio constante de Lisboa para o Brasil é ainda mais surpreendente quando se sabe que ela foi editada pela Impressão Régia, no Rio de Janeiro, e que, portanto, poderia ser adquirida na cidade sem necessidade de importação. ${ }^{33}$

Isso não teria ocorrido - ou, ao menos, não tão rapidamente - se nosso já conhecido Antonio de Araújo e Azevedo não tivesse embarcado trazendo consigo, na nau Medusa, uma tipografia completa. Ela havia chegado a Lisboa há pouco, vinda da Inglaterra, para ser usada na Secretaria de Estado dos Negócios Estrangeiros e da Guerra, e se encontrava ainda encaixotada, facilitando seu transporte junto com a documentação e maquinaria trazidas pela família real.

Assim que a corte se instalou, ficou evidente a felicidade de se haver embarcado uma tipografia, visto que era impossível manter a sede do Reino na América, se se mantivesse a interdição de imprimir no Brasil. ${ }^{34}$ Assim, D. João, reconhecendo a "necessidade, que há da oficina de impressão nestes meus estados", criou, por Decreto 13 de maio de 1808, a Impressão Régia, na qual seriam impressos, com exclusividade, os documentos oficiais, os livros e demais papéis que se desejasse estampar, ${ }^{35}$ o que lhe garantiu o monopólio da impressão no Rio de Janeiro até 1821, quando o funcionamento de tipografias particulares passou a ser autorizado.

Instalada, a Impressão Régia do Rio de Janeiro não se limitou a colocar em letra de forma os éditos, avisos e alvarás, mas deu à luz toda sorte de escritos, inclusive obras poéticas e ficcionais. A julgar pelo que restou dessa produção, a imprensa foi inserida rapidamente nas práticas de adulação dos poderosos, pois foram impressas grandes quantidades de poemas em elogio

${ }^{32}$ Mantém-se a predominância de negociantes no envio de exemplares para a colônia: 25 pedidos foram assinados por pessoas ligadas ao comércio, dentre as quais se destaca João Gomes de Oliveira, responsável por 9 pedidos, seguido por Francisco Rolland, autor de 6 solicitações.

${ }_{33}$ Marilia de Dirceo, por T.A.G., nova edição, Rio de Janeiro, na Impressão Regia, com licença de S.A.R., 1810, 3 partes.

${ }^{34}$ Apesar de algumas tentativas frustradas, como a que empreendeu Antonio Isidoro da Fonseca ao tentar instalar uma casa tipográfica, no Rio de Janeiro, em 1747, a possibilidade de imprimir permaneceu vetada pela Coroa portuguesa até 1808 . O Brasil foi o $12^{\circ}$ local da América Latina a ter uma tipografia oficialmente instalada. Sobre a Impressão Régia do Rio de Janeiro, ver: Márcia Abreu, "Criação da Impressão Régia”, in Circe Bittencourt (org.), Dicionário de datas da história do Brasil, São Paulo, Contexto, 2007, p. 131-134. Ver também Simone Cristina Mendonça de Souza, Primeiras impressões: romances publicados pela Impressão Régia do Rio de Janeiro (1808-1822). Tese de Doutorado disponível em www.caminhosdoromance.iel.unicamp.br.

${ }^{35}$ Decreto de 13 de maio de 1808, Código Brasiliense, ou Colecção das Leis, etc., promulgadas no Brasil, tomo I, Rio de Janeiro, 1811. 
aos soberanos, recitativos para as datas natalícias de membros da família real, orações congratulatórias etc.

Embora muito diferente desse tipo de escritos, Marilia de Dirceu esteve entre as primeiras obras a serem impressas, vindo à luz, em três volumes, em 1810. Nesse mesmo ano, o livreiro Paulo Martin anunciava, juntamente com O Plutarco revolucionário, um "Catálogo dos folhetos impressos à custa de Paulo Martin Filho, que se acham na sua loja na rua da Quitanda no 34", no Rio de Janeiro, no qual incluía, como estando no prelo, "Marilia de Dirceu, por Gonzaga, 3 vol.", ${ }^{36}$ sendo considerado, por esse motivo, o primeiro editor instalado no Brasil. ${ }^{37}$

Francês de Tours, Martin atuava como livreiro em Portugal desde 1777,38 e como editor, pelo menos desde 1804, quando submeteu à censura um pedido de autorização para imprimir o "Catalogo de varios Livros impressos á custa de Paulo Martin, e de outros q'o mesmo tem em grande numero, com os preços por q'se vendem Encadernados na sua Loja de fronte do Chafariz do Loreto, $\mathrm{n}^{\circ} .6 ",{ }^{39} \mathrm{em}$ Lisboa, no qual se arrolam 143 obras de assuntos tão variados como Medicina e Religião, Química e Belas Letras. ${ }^{40}$

Como livreiro, Martin atuava no Brasil desde o final do século XVIII, quando solicitou autorização para encaminhar seu filho à cidade do Rio de

\footnotetext{
${ }^{36}$ O catálogo é reproduzido em: Maria Beatriz Nizza da Silva, Cultura no Brasil Colônia, Petrópolis, Vozes, 1981. (grifo meu)

${ }^{37}$ Em O bibliófilo aprendiz, de 1975, Rubens Borba de Moraes afirmava: "muito romance impresso na Imprensa Régia era editado por Paul Martin. Esse Paul Martin, filho, era francês e foi, se não me engano, o primeiro editor que houve no Brasil. Mandava imprimir romances, novelas, folhetos políticos, poemas, orações fúnebres, que vendia na sua livraria da Rua da Quitanda n ${ }^{\circ}$ 34" (Rubens Borba de Moraes, O bibliófilo aprendiz, São Paulo, Companhia Editora Nacional, 1975, 2.ed., p. 173). Em 1993, Rubens Borba de Moraes reafirma, em tom menos dubitativo: "a publicação de romances [na Impressão Régia] deve-se à iniciativa de Paulo Martin filho, nosso primeiro editor" (Rubens Borba de Moraes, "A Impressão Régia do Rio de Janeiro: origens e produção", in Ana Maria de Almeida Camargo e Rubens Borba de Moraes, Bibliografia da Impressão Régia do Rio de Janeiro, São Paulo, Edusp, Livraria Kosmos Editora, 1993, vol. I, p. XXIX).

${ }^{38}$ Ao menos esta é a data do primeiro Catálogo de sua livraria remetido à censura portuguesa. "Catálogo dos Livreiros e Editores”, RMC, ANTT, caixa 10.

${ }^{39}$ RMC, ANTT, caixa 53, 1804, nov., 24 (grifo meu). Ver: Márcia Abreu, "Impressão Régia do Rio de Janeiro: novas perspectivas", in Convergência Lusíada, n. 21, Real Gabinete Português de Leitura, Centro de Estudos Pólo de Pesquisa sobre Relações Luso-brasileiras, 2005, p. 199-222.

${ }^{40}$ Sobre os catálogos de livros, ver: Manuela D. Domingos, "Os catálogos de livreiros como fontes da história da livro: o caso dos Reycend”, Revista da Biblioteca Nacional, s. 2, vol. 4, Lisboa, 1989, p. 83-102.
} 
Janeiro, "aonde hia aprender o Commercio em geral". ${ }^{41}$ Paulo Agostinho Martin, o filho, trabalhou bem, fazendo com que a casa Paulo Martin fosse a mais importante livraria do período colonial, realizando remessas regulares e volumosas de obras de Lisboa para venda no Rio de Janeiro. A partir de 1799, há pedidos de autorização para envio de listas e listas de livros, cada vez mais extensas, de Lisboa para o Rio de Janeiro. Até 1807, ele havia sido responsável por 23 pedidos de licença apresentados aos organismos de censura lusitanos, nos quais solicitava autorização para a remessa de 497 obras de Belas Letras. A transferência da corte para o Brasil parece ter dado bom impulso aos seus empreendimentos, pois, além de se tornar editor, utilizando os prelos da Impressão Régia, manteve uma constante importação de impressos de Lisboa, submetendo, entre 1808 e 1826, 66 pedidos de licença e obtendo autorização para o envio de 699 obras de Belas Letras para o Rio de Janeiro. ${ }^{42}$

Se a transferência da corte parece ter favorecido seus negócios, a instalação da Impressão Régia no Rio de Janeiro parece tê-lo beneficiado também em suas atividades comerciais em Lisboa. Em 1812, ele submeteu à aprovação da censura lisboeta o "Catalogo das Obras impressas no Rio de Janeiro e que se achaõ de venda_em Lisboa, na loja de Paulo Martin e Filhos, $\mathrm{n}^{\circ} .6$ defronte do Chafariz do Loreto". ${ }^{43}$ Invertendo o fluxo dos livros que, durante séculos, partiram de Portugal rumo ao Rio de Janeiro, Paulo Martin solicitou autorização para divulgar, em Lisboa, a venda de 45 títulos produzidos pela Impressão Régia do Rio de Janeiro, compondo um catálogo de obras variadas de Direito, Geografia, Medicina, Matemática, Economia, Agricultura, Biologia e Belas Letras. ${ }^{44}$ É difícil supor que ele tivesse sido o editor de todos os livros anunciados, mas, de qualquer forma, mostrou tino na seleção dos textos a

41 "Junta do Comércio", livro 132, Registro de Consultas 1799-1801, fls. 32v-33-33v-34 (ANTT). Este documento é também analisado por Lúcia Maria Bastos P. Neves, "Comércio de livros e censura de idéias: a actividade dos livreiros franceses no Brasil e a vigilância da Mesa do Desembargo do Paço (1795-1822)", Ler História, n. 23, Lisboa, 1992, p. 61-78, e por Fernando Guedes, O livro e a leitura em Portugal. Subsidios para sua história (século XVIII - XIX), Lisboa, Verbo, 1987.

${ }^{42}$ Ver Márcia Abreu, O caminho dos livros, op. cit.

${ }^{43} \mathrm{O}$ manuscrito obteve autorização de impressão em 17 de outubro de 1812 e autorização para circular em 27 de outubro de 1812. RMC, ANTT, caixa 72 (1812 - X - 27). Grifo meu.

${ }^{44} \mathrm{O}$ "Catálogo" está transcrito na íntegra em Márcia Abreu, "Impressão Régia do Rio de Janeiro: novas perspectivas", in Convergência Lusiada, n. 21, Real Gabinete Português de Leitura, Centro de Estudos Pólo de Pesquisa sobre Relações Luso-brasileiras, 2005, p. 199222. O conjunto de obras de Belas Letras anunciado no "Catálogo" é reduzido, contando com apenas 10 títulos - poemas, tragédias, um elogio e um sermão. Curiosamente, não se faz referência a um único romance - gênero ao qual, segundo a historiografia brasileira, se ligaria a atividade de Paulo Martin como editor. 
anunciar. Nas Belas Letras, incluiu uma primeira edição - "Elogio do Ill ${ }^{\text {mo }}$. e $\mathrm{Ex}^{\mathrm{mo}}$. Senhor Sebastiaõ Jozé de Carvalho e Mello, Marquez de Pombal"45 -, títulos esgotados, como "O Uraguay. Poema de Jozé Basilio de Gama"46 e obras de sucesso, como os poemas e traduções de Bocage ${ }^{47}$. Pela primeira vez, para ler a obra de um poeta nascido na América, como Basílio da Gama, não era necessário comprá-la em Lisboa e remetê-la para sua terra natal. Ao contrário, os moradores de Lisboa é que teriam de aguardar a chegada da edição de O Uraguay, impressa no Rio de Janeiro e vendida por Paulo Martin em Lisboa.

A exportação de livros produzidos no Rio de Janeiro para venda em Portugal indica que o material produzido na América tinha vantagens sobre o saído à luz em Lisboa. Seja por seus preços serem interessantes, seja pela qualidade gráfica, seja pela singularidade dos títulos, valia a pena o sacrifício de submeter-se às imposições da censura, às regulamentações da importação e aos prazos dos transportes para fazê-los chegar às mãos daqueles que tinham permanecido na Europa.

Nesses casos, a relação secular se invertia duplamente: não apenas os livros viajavam do Brasil para Portugal, mas também era necessário obter licença no Rio de Janeiro para fazê-los embarcar.

A transferência da corte e a abertura dos portos fizeram com que fosse necessário instalar um órgão encarregado de controlar a circulação de livros no Brasil. Assim, em 22 de abril de 1808, foi criada, por Alvará Régio, a Mesa do Desembargo do Paço, no Rio de Janeiro, a qual, entre diversos afazeres,

45 "Elogio do Ill $^{\mathrm{mo}}$. e Ex ${ }^{\mathrm{mo}}$. Senhor Sebastiaõ Jozé de Carvalho e Mello, Marquez de Pombal. 1811 em 40." [A edição da Oração funebre (n. ${ }^{\circ}$ 1520) feita no Brazil, saiu com o titulo seguinte: Elogio do ill.mo e ex.mo sr. Sebastião José de Carvalho e Mello, marquez de Pombal conde de Oeiras, etc. Rio de Janeiro, sem designação de typ., 1811. 4. ${ }^{\circ}$ gr de 14 pag. - (...) mais tarde publicada n'O Investigador Portuguez em Inglaterra (jul. 1817, p/ 3-15]. Entre aspas estão as indicações feitas no Catálogo de Paulo Martin. Entre colchetes, informações fornecidas por Silva, Innocencio Francisco da. Diccionario Bibliographico Portuguez. Ophir, Biblioteca Virtual dos Descobrimentos Portugueses, 9, 2001.

46 "O Uraguay, Poema de Jozé Basilio de Gama. 1811 em 8․" Publicado em 1769 em edição pouco superior a mil exemplares, é bastante provável que já não houvesse exemplares disponíveis - ou que estivessem se tornando raros - em 1811.

${ }^{47}$ O Catálogo refere 4 traduções e uma obra de Bocage sucessivamente editadas em Portugal: "Ericia, ou a Vestal, Tragedia, traduzida do Francez por Bocage. $1811 \mathrm{em} 8^{\circ}$."; "O Consorcio das Flores, traducçaõ de Lacroix, por Bocage. 1811 em 8․"; "Eufemia, ou o Triunfo da Religiaõ. Drama de D'Arnaud, traduzido por Bocage. 1811 em $8^{\circ}$."; "Os Jardins, ou a Arte de aformosear as paisagens. Poema de Delille, traduzido por Bocage. 1812 em $8^{\circ}$."; "Improvisos de Bocage na sua mui perigosa enfermidade, dedicados aos seos bons amigos. $1810 \mathrm{em} 8^{\circ}$." 
cuidava da censura aos livros que chegavam e partiam, bem como dos manuscritos que se pretendiam fazer publicar na Impressão Régia.

Os processos mais trabalhosos eram os relativos à liberação e retirada de livros das alfândegas. Aqueles enviados de Portugal, em geral, chegavam com licenças emitidas pelos órgãos censores lisboetas - cabendo, então, verificar se os ali desembarcados correspondiam exatamente à licença obtida em Lisboa. Já os impressos remetidos de outras localidades necessitavam ser examinados ao chegar ao Brasil. Em ambos os casos, o trabalho era grande, já que, por ordem real, era necessário assegurar-se "exaustissimamente que jamais sejão admitidos a despacho por esta Alfandega Livros e Impressos de qualquer natureza sem a competente licença da Meza do Desembargo do Paço do Brasil", de modo que nem o menor dos papéis sairia dos portos sem exame. ${ }^{48}$

Restaram registros de 84 pedidos de licença, dirigidos à Mesa, visando obter a liberação de 1.190 diferentes títulos de Belas Letras. A maior parte dos responsáveis pelos pedidos não se preocupou em indicar a procedência dos livros, mas dentre os que o fizeram, a maioria indicou a França como local de onde partiam as obras, seguida de perto pela Inglaterra. Alguns transportavam livros de locais mais distantes, ou menos óbvios, como José Barreto Junior, "Negociante da Praça de Bengalla”, que em 1812 "trouxe em sua Companhia um bahú com livros", no interior do qual havia duas obras de Belas Letras, ambas pertencentes ao conjunto das preferidas no Rio de Janeiro: "Carolina Lichtfield" e "Camões". Naquele tempo de viagens longas e demoradas, é espantoso reencontrá-lo, no mesmo ano, apresentando novo pedido para entrar no Brasil com livros, desta vez, informando que os "trouxe em sua Companhia da Cidade de Calcutá para este Rio de Janeiro". No conjunto de obras trazidas consigo reaparecem "Luziadas e Rithmas de Camões" e "Carolina de Lichtfield". Seriam livros que ele apreciava ler durante suas viagens? Ou, entre seus "negócios", encontrava-se o comércio de livros?49 De qualquer forma, chama a atenção a sintonia entre os livros que transportava e os títulos preferidos no Rio de Janeiro.

\footnotetext{
${ }^{48}$ Documento datado de 12 de janeiro de 1809. Arquivo Nacional do Rio de Janeiro (doravante chamado ANRJ) - Mesa do Desembargo do Paço (doravante denominado MDP).

${ }^{49}$ Além de "Luziadas e Rithmas de Camões" e "Carolina de Lichtfield", na segunda viagem, José Barreto Júnior trouxe consigo "Almeida Felix independente"; "Historia de Estevanillo"; "Fables amusantes"; "Historia Americana"; "Carta Universal"; "Gerusalemme Liberata Di Torquato Tasso"; "Epitome poético"; "Livros escritos em letra perciana”. ANRJ, MDP, Licenças, caixa 819 (antigas 169).
} 
Apesar da diversidade de procedências, a lista dos livros mais referidos nos pedidos apresentados à Mesa do Desembargo do Paço contém importantes semelhanças com aquela composta pelas obras mais requeridas junto à censura lisboeta entre 1808 e 1826. Considerando as obras de Belas Letras, há, novamente, uma forte presença de obras ficcionais, responsáveis por 45\% dos títulos mais solicitados: Aventuras de Telêmaco, de Fénelon; Historia de Gil Braz de Santilhana, de Lesage; Viagem de Anacharsis, de Barthélemy; O Engenhoso Fidalgo D. Quixote de la Mancha, de Cervantes; Robinson Crusoé, de Defoe; Obras de Lesage; Paulo e Virginia, de Saint-Pierre; Obras de Prevost; Scenes de la vie du grand monde, de Edgeworth. ${ }^{50}$

Livros como Aventures de Télémaque, Histoire de Gil Blas de Santillane e Don Quijote de la Mancha parecem ter sido sucessos incontestáveis em qualquer parte do mundo, chegando ao Brasil seja por meio de Portugal, seja a partir de outros países europeus. Reforçando a extraordinária presença da obra de Fénelon no mundo, ampliou-se a gama de edições compostas em diversas línguas e em várias combinações: há pedidos para "Aventures de Telemaque Anglais=Espagnol", "Aventures de Télémaque en Anglais", "Aventures de Télémaque en Anglais et Français", "Aventures de Télémaque en Espagnol”, "Aventures de Télémaque en Italien et français”, “Télémaque en Espagnol et français". ${ }^{11}$ Diversificou-se também o interesse pelos escritos do francês Alain René Lesage, que passou a ser conhecido não apenas pelas aventuras de Gil Blas, mas também por suas obras completas. Nesse caso, os leitores tinham que ter conhecimentos da língua francesa, pois não havia tradução disponível para as Oeuvres, de Lesage, nem para a maior parte dos livros solicitados com mais freqüência.

Diferentemente do que acontecia em Portugal, a lista dos livros mais requisitados junto à Mesa do Desembargo do Paço no Rio de Janeiro era fortemente marcada por obras estrangeiras. Se, entre as mais requisitadas em Lisboa, havia cinco títulos compostos originalmente em português, nos pedidos submetidos à censura instalada no Brasil não constava sequer um título em português entre os mais procurados. Tampouco havia traduções para o português para $60 \%$ deles. $\mathrm{O}$ francês, que era bastante presente como

\footnotetext{
${ }^{50}$ Além das obras ficcionais, compõem a lista dos 10 títulos mais remetidos ao Rio de Janeiro as seguintes obras: Fables de La Fontaine, de La Fontaine; Voyage de La Pérouse au tour du Monde, de Milet Mureau; Jerusalem liberata, de Tasso; Oeuvres, de Racine; Oeuvres, de Molière; Oeuvres, de Corneille; Oeuvres, de Boileau; Oeuvres, de Lesage; Oeuvres, de Prévost; Le poeme sur la Religion, de Racine; Obras, de Virgílio; Oeuvres, de Gresset; La Henriade, de Voltaire. ${ }^{51}$ ANRJ, MDP, caixas 818, 819, 820 (antigas 168, 169, 170).
} 
a língua de origem dos livros mais mencionados nos pedidos submetidos à censura lisboeta, tornou-se dominante, respondendo por $75 \%$ da origem dos textos. Há, ainda, o curioso caso do livro Tales of Fashionable Life, escrito em inglês por Maria Edgeworth, que, entretanto, jamais foi solicitado em inglês, e sim na tradução francesa intitulada Scenes de la vie du grand monde, o que, na prática, reduz a presença da língua inglesa entre os mais solicitados a apenas um título - The Life and Strange Surprizing Adventures of Robinson Crusoe, de Daniel Defoe. Da mesma forma, a ninguém ocorreu a idéia de se referir à obra de Torquato Tasso em italiano e sim sempre como Jerusalem délivrée, o que amplia ainda mais a presença do francês.

Essas peculiaridades, observáveis nos pedidos submetidos ao Desembargo do Paço no Rio de Janeiro, talvez se expliquem pelo fato de as requisições terem sido elaboradas, sobretudo, por particulares, ao contrário do que ocorria em Portugal, onde a maior parte dos requerentes era formada por livreiros. ${ }^{52}$

Dentre essas dezenas de pedidos, cotidianamente apresentados por particulares à Mesa do Desembargo do Paço, no Rio de Janeiro, um chama atenção, pois era destinado a Daniel Pedro Müller, filho do nosso já bem conhecido João Guilherme Christiano Müller. Ele vivia no Brasil desde 1802, quando, por decreto real, assumiu o posto de capitão de infantaria em São Paulo, acompanhando, como ajudante de ordens, o novo governador da capitania de São Paulo, Antônio José de Franca e Horta. ${ }^{53}$ Quando a corte chegou ao Rio de Janeiro, ele já havia sido promovido a sargento-mor, tendo participado dos preparativos dos festejos para recepcionar a família real. ${ }^{54}$ Logo depois, em novembro de 1808, passou a tenente-coronel de infantaria, fazendo uma carreira militar sempre ascendente. Além de ser militar, Daniel Pedro Müller dedicou-se intensamente às Ciências, às Letras e às Artes. ${ }^{55}$ Talvez por isso,

\footnotetext{
${ }^{52}$ Entre 1769 e 1807 , dos 205 pedidos submetidos à censura portuguesa, 116 foram assinados por livreiros ou negociantes. Entre 1808 e 1826, dos 357 pedidos apresentados em Lisboa, 226 foram de responsabilidade de gente ligada ao comércio. No Rio de Janeiro, entre 1808 e 1821, das 84 solicitações, apenas 30 foram encaminhadas por comerciantes.

53 "Daniel Pedro Müller", in Grande Enciclopédia Portuguesa e Brasileira, Lisboa e Rio de Janeiro, Editorial Enciclopédia, vol. XVIII, sem data, p. 115-116.

${ }_{54}$ Neves, Lúcia Maria Bastos P. "Luzes nas bibliotecas de Francisco Agostinho Gomes e Daniel Pedro Muller, dois intelectuais luso-brasileiros", Congresso Internacional O Espaço Atlântico de Antigo Regime: poderes e sociedades, mimeo.

55 "Daniel Pedro Müller", in Grande Enciclopédia Portuguesa e Brasileira, Lisboa e Rio de Janeiro, Editorial Enciclopédia, vol. XVIII, sem data, p. 115. Segundo Lúcia M. B. P. das Neves, "Daniel Pedro Müller destacou-se por organizar o Instituto Topográfico de São Paulo, iniciado em 1806, por ordem do governador Franca e Horta, com uma aula para a formação de engenheiros, nomeando-o para lente da mesma. Nessa visão, foi o autor do primeiro mapa gravado da Capitania de São Paulo". Neves, L. M. B. P., "Luzes nas bibliotecas...", op. cit.
} 
por ocasião da morte de João Guilherme Christiano Müller, em outubro de 1814 , coube a ele parte importante de sua biblioteca. ${ }^{56}$

Nesse momento, assim como havia ocorrido no caso de Paulo Martin, as relações se inverteram. Se, durante 22 anos, Christiano Müller atuou como censor, verificando listas e listas de obras para autorizar ou não sua circulação no Reino e nas colônias, agora eram seus livros que se tornavam objeto de escrutínio ao serem remetidos de Lisboa para o Rio de Janeiro. Assim, para que a biblioteca pudesse atravessar o Atlântico, foi elaborada uma listagem, contendo centenas de títulos em várias línguas.

Quando censor, Müller muitas vezes se zangava com a maneira como se elaboravam os pedidos de licença. Logo no início de sua carreira como censor, aborreceu-se fortemente com a maneira como fora organizada a listagem dos livros cuja liberação nosso já bem conhecido Paulo Martin pretendia obter. Em 16 de agosto de 1796, antes de principiar o comentário dos livros, Müller lembrava que, "no $§ 20$ de seu Alvara de 30 de Julho 1795", se ordenava que os róis de livros fossem "formados "com ordem clareza, e exactidaõ", o que implicava "indicar os Lugares onde foraõ feitas as Ediçoẽs das respeitivas obras, e de copiar os nomes inteiros dos Autores, e de naõ pôr nem mais nem menos Livros nos differentes Catalogos, que se apresentaõ as differentes Autoridades". O encarregado da preparação da lista de livros submetida por Paulo Martin não havia tomado nenhum desses cuidados: em primeiro lugar, "omittio a mençaõ das datas e Lugares de impressaõ, o que (...) caus[ou] muito embaraço inutil ao Censor custando-lhe muita mais parte de seu tempo (cuja

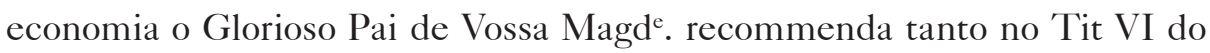
Regimento da Meza Censória) do que alias gastaria”; e, em segundo, apresentou um livro a mais na listagem submetida ao Santo Ofício do que na entregue ao Ordinário. A falta de indicação das edições e dos nomes dos autores tornava, muitas vezes, custosa a identificação do texto, o que, como declarou Muller, "difficult[ava] a perquisiçaõ necessaria, com varias conjecturas antes de acertar o verdadeiro". ${ }^{57}$

\footnotetext{
${ }^{56}$ Segundo Inocêncio Francisco da Silva, "O bisneto do academico Muller, sr. Frederico E. Payant, actual chefe da estação do cabo submarino, em Lisboa (junto da estação central dos telegraphos do reino), e que tem dedicado ocios ao cultivo das letras, sendo um dos collaboradores da Revista contemporanea de Portugal e Brazil, ainda possue de seu illustre bisavô livros e mss. ineditos". Innocencio Francisco da Silva, Diccionario Bibliographico Portuguez, Lisboa, Imprensa Nacional, 1858, tomo III, p. 270.

${ }^{57}$ ANTT, RMC, caixa 28, 1796, ago., 19.
} 
Vinte e dois anos depois, seu colega de ofício, o censor José da Silva Lisboa, passou pelas mesmas dificuldades que ele ao examinar a lista apresentada por seu filho Daniel..$^{58} \mathrm{O}$ rol de livros apresentado era composto por 755 títulos, publicados em alemão, holandês, português, francês, inglês, latim, espanhol e italiano, contendo, sobretudo, obras de cunho religioso, seguidas de textos de Belas Letras e escritos sobre Ciências e Artes. ${ }^{59} \mathrm{O}$ responsável pela elaboração da listagem raras vezes anotou os nomes dos autores e praticamente jamais informou outros dados bibliográficos, como o local de edição.

Assim como a forma de apresentação do material submetido a exame por Paulo Martin havia perturbado Müller, a listagem de livros apresentada no Rio de Janeiro dificultou a tarefa de Lisboa, que se queixou em termos semelhantes aos de seu colega:

Naõ posso interpôr o meu parecer que V. Mage. Mandou quanto aos livros escriptos em Lingua Allemãa que ignoro, e que indico com o sinal x. Quanto aos outros, parece-me que são dignos da Licença pedida, tendo só duvida no = Abregé de Histoire Universalle de Voltaire, que noto na pag. 2 f. com algarismo 2., bem que he a obra de credito desse Author, em que naõ dogmatizou as suas usuaes opiniões infieis: $=$ De l'Esprit 3 volumes; como naõ se declara o Author, tenho suspeita que seja a obra de l'Esprit de Helvecio, que he Materialista. ${ }^{60}$

A listagem apresentava diversos inconvenientes: além da má qualidade da informação apresentada e do desconhecimento do censor acerca das obras publicadas em alemão, havia textos proibidos dentro do conjunto. Apesar de todos esses inconvenientes, José da Silva Lisboa não mostrou grande perturbação e pronunciou-se pela liberação dos livros: "como a lista contem muitos livros excellentes, ou indifferentes, e são para o uso de seu dono, filho do mui douto e pio Censor Muller que taõ bem serviu o Estado em Portugal, entendo ser deferivel a Licença requerida".

O parecer elaborado por Lisboa deixa clara uma das características da censura luso-brasileira que, agindo de acordo com princípios próprios ao Antigo Regime, avaliava as situações conforme as pessoas envolvidas, estando

\footnotetext{
${ }^{58}$ ANRJ, Desembargo do Paço, Licenças, caixa 819 (antigas 169), pacote 1, doc. 17.

${ }^{59}$ Sobre os livros recebidos por Daniel Pedro Müller, ver Neves, Lúcia Maria Bastos P. "A biblioteca de Daniel Pedro Muller e as luzes luso-brasileiras", XXIV Reunião da Sociedade Brasileira de Pesquisa Histórica, Curitiba, 26 a 30 de julho de 2004, mimeo. Lúcia Maria Bastos P. Neves, "Luzes nas bibliotecas de Francisco Agostinho Gomes e Daniel Pedro Müller, dois intelectuais luso-brasileiros", Congresso Internacional O Espaço Atlântico de Antigo Regime: poderes e sociedades, mimeo.

${ }^{60}$ ANRJ, Desembargo do Paço, Licenças, caixa 819 (antigas 169), pacote 1, doc. 17 [6].
} 
muito longe da idéia de que a lei deveria valer de forma igual para todos. ${ }^{61}$ Ele percebeu a existência de livros possivelmente duvidosos e de outros claramente proibidos, mas autorizou sua entrada, tendo em vista o merecimento de seus proprietários, pai e filho, ambos diligentes servidores do Estado português.

Acompanhando a tramitação do processo, o escrivão da Mesa do Desembargo, Bernardo José de Souza Lobato, foi mais minucioso e chamou a atenção para o fato de que "na ordem dos numeros da Lista juncta dos Livros pertencentes a Daniel Pedro Muller falta o $n^{\circ}$. 8, e 9 das respectivas Caixas, q. parece devem conter Livros segundo o titulo da mesma Lista". Além da falta de referência ao conteúdo de dois caixões de livros, a forma da numeração parecia-lhe estranha por existirem duas caixas número 1 (uma delas renumerada como " $\mathrm{N}^{\circ} .0$ "). Lobato perguntava-se "se isto procederá da inversão dos numeros e d'engano de quem transcrevêo a Lista" e se a confusão numérica não poderia "dar motivo a alguma duvida á occasião do despacho n'Alfandega" ${ }^{62}$

A quantidade de irregularidades não era pequena, pois a falta de menção ao conteúdo de dois caixotes deve ter lembrado a Lobato dos inúmeros subterfúgios utilizados por aqueles que tencionavam burlar a censura, produzindo listas truncadas, acrescentando títulos após a aprovação, transportando obras de maneira oculta, encadernando textos proibidos debaixo das mais inocentes coberturas etc. ${ }^{63}$ Mesmo assim, Daniel Pedro Müller conseguiu, em 4 de maio de 1818, um despacho favorável, permitindo a liberação dos livros na alfândega, "menos á obra intitulada les [Esprit] de q'se remetera hum exemplar a esta Meza". ${ }^{64}$

O sistema de censura, que visava manter um controle absoluto sobre os livros em circulação, mostrava suas brechas. Por meio do exame dos documentos ali produzidos, é possível perceber a intensa circulação de impressos no Rio de Janeiro desde meados do século XVIII, a qual se intensificou depois da transferência da família real. A partir de 1808, não apenas se tornou possível imprimir livros na América Portuguesa, como se ampliou o comércio de livros entre os dois lados do Atlântico. Além disso, invertendo uma ordenação secular, que fazia com que os livros saíssem da Europa em direção ao

\footnotetext{
${ }^{61}$ Ver, por exemplo, o estudo de Luiz Carlos Villalta acerca das concessões de licença para leitura de livros proibidos. Villalta, Reformismo ilustrado..., op. cit.

${ }^{62}$ ANRJ, Desembargo do Paço, Licenças, caixa 169, pacote 1, doc. 17 [8].

${ }^{63}$ Ver, a respeito, Abreu, Os caminhos..., op. cit.

${ }^{64}$ A documentação encontra-se danificada justamente no local em que está indicado o título da obra a ser remetida para exame. Muito provavelmente trata-se de De l'Esprit, pois foi o livro que despertou maior dúvida sobre José da Silva Lisboa.
} 
Brasil, surgiram casos em que as obras lidas em Portugal haviam sido produzidas no Rio de Janeiro.

Afora o sistema legal, havia os que burlavam a fiscalização, escondendo livros e disfarçando escritos. Outros, como os censores, liam seguidamente obras proibidas para avaliá-las e acabavam por constituir bibliotecas em que havia exemplares de obras vetadas ao público amplo. Em algumas circunstâncias, o acaso fazia com que centenas de livros fossem transportados, sem qualquer exame, como aconteceu com a biblioteca de Antonio de Araújo e Azevedo, a qual, após seu falecimento, foi adquirida e incorporada ao acervo da Biblioteca Real, que permaneceu no Brasil mesmo depois do regresso de D. João e da independência do Brasil.

Ao decidir-se pela transferência da corte para o Rio de Janeiro, dificilmente se imaginaria que tantas modificações iriam se processar. Da mesma forma, na noite entre 25 e 26 de novembro de 1807, João Guilherme Christiano Müller e Antonio de Araújo e Azevedo poderiam sequer imaginar que suas bibliotecas atravessariam o Atlântico para nunca mais regressar. 